\title{
CONVEXITY ACCORDING TO THE GEOMETRIC MEAN
}

\author{
CONSTANTIN P. NicUlescu
}

\begin{abstract}
We develop a parallel theory to the classical theory of convex functions, based on a change of variable formula, by replacing the arithmetic mean by the geometric one. It is shown that many interesting functions such as exp, sinh, $\cosh , \sec , \csc$, arc sin, $\Gamma$ etc illustrate the multiplicative version of convexity when restricted to appropriate subintervals of $(0, \infty)$. As a consequence, we are not only able to improve on a number of classical elementary inequalities but also to discover new ones.
\end{abstract}

Mathematics subject classification (1991): 26A51, 26D05, 26D07, 51M16.

Key words and phrases: convex function, $A M-G M$ Inequality, elementary symmetric functions.

\section{REFERENCES}

[1] E. ARTin, The Gamma Function, Holt, Rinehart and Winston, New York, 1964. English translation of German original, Einführung in die Theorie der Gammafunktion, Teubner, 1931.

[2] H. Bohr AND J. Mollerup, Laerebog i mathematisk Analyse, vol. III, pp. 149-164, Kopenhagen, 1922.

[3] A. Engel, Problem-Solving Strategies, Springer-Verlag, 1998.

[4] I. S. Gradshteyn AND I. M. RyZhik, Table of Integrals, Series and Products, Academic Press, 1996. (CD-ROM version)

[5] G. Hardy, J. E. LitTlewood and G. Polya, Inequalities, Cambridge Mathematical Library, 2nd ed., 1952, Reprinted 1988.

[6] A. Horn, On the eigenvalues of a matrix with prescribed singular values, Proc. Amer. Math. Soc. 5 (1954), 4-7.

[7] C. H. Kimberling, Some Corollaries to an Integral Inequality, Amer. Math. Month., 81 (1974), 269-270.

[8] A. W. Marshall And I. OlKIn, Inequalities: Theory of Majorization and its Applications, Academic Press, 1979.

[9] D. MiHET, An extension of the Inequality of Huygens, Revista Matematica din Timisoara, 1 (1990), no. 2, pp. 6-7. (Romanian)

[10] P. MonTEL, Sur les functions convexes et les fonctions sousharmoniques, Journal de Math. (9), 7 (1928), 29-60.

[11] T. Popoviciu, Sur certaines inégalités qui caractérisent les fonctions convexes, Analele Stiintifice Univ. "Al. I. Cuza", Iasi, Sectia Mat., 11 (1965), 155-164.

[12] A. Wayne Roberts and Dale E. VArberg, Convex Functions, Academic Press, New York and London, 1973.

[13] SAKS S., Sur un theoreme de M. Montel, C. R. Acad. Paris, 187 (1928), 276-277.

[14] H. WEYL, Inequalities between two kinds of eigenvalues of a linear transformation, Proc. Nat. Acad. Sci. U.S.A., 35 (1949), 408-411.

[15] E. T. WhitTAKer And G. N. Watson, A course on Modern Analysis, 4th. ed., Cambridge, 1927. 